\title{
The Financial Dimension of Integrated Behavioral/Primary Care
}

\author{
Nicholas A. Cummings • William T. O'Donohue • \\ Janet L. Cummings
}

(C) Springer Science+Business Media, LLC 2009

\begin{abstract}
There are two reasons why mental health, now more appropriately termed behavioral healthcare, is declining: (a) a lack of understanding among psychotherapists of healthcare economics, particularly the intricacies of medical cost offset, and (b) our failure as a profession to see the importance of behavioral interventions as an integral part of the healthcare system inasmuch as the nation pays for healthcare, not psychosocial care. This paper will briefly describe the rapid changes in the economics of healthcare during the past 75 years, including the post World War II enthusiastic espousal of psychotherapy by the American public which was followed by a precipitous decline as our outcomes research in behavioral care remained ignorant of financial outcomes, leaving it to the government and managed care to arbitrarily curtail escalating mental health costs. At the present time psychology is on the cusp of becoming part of the healthcare system through integrated behavioral/primary care, renewing the primacy of financial considerations such as return on investment (ROI) and medical cost offset, as well as an urgency that we avoid the mistakes that are emerging in some flawed implementations of integrated care.
\end{abstract}

Keywords Healthcare economics - Medical cost offset . Integrated behavioral/primary care

N. A. Cummings $(\varangle) \cdot$ W. T. O’Donohue $\cdot$ J. L. Cummings

University of Nevada, Reno, NV, USA

e-mail: CummFound@aol.com

N. A. Cummings · W. T. O'Donohue · J. L. Cummings The Cummings Foundation for Behavioral Health, Reno, NV, USA
Very few people do anything creative after the age of 35 . The reason is that very few people do anything creative before the age of 35 .

Joel Hildebrand (2008)

\section{A Brief History of Healthcare Economic Developments: 1929-2009}

When the Great Depression (1929-1941) engulfed the United States, medicine had come of age, transitioning from an often apprentice trained profession to accredited medical schools and state laws with licensure governing its practice. Essentially medicine was all of healthcare, with everything else (e.g., nursing) being ancillary. Before World War II there were about 200 psychologists in the private practice of psychotherapy scattered about the nation, most of whom were women practicing with a master's degree and seeing children. These were tolerated by the 5,000 psychiatrists in existence at the time, most practicing without board certification.

Physicians were far from wealthy in spite of a shortage. They were dedicated, often working long hours as they were determined to see every patient that wanted to be seen, never refusing a house call even at night, and never remanding an unpaid bill to a collection agency as such was considered unethical and unprofessional. There was no healthcare insurance, few patients could pay in those economically depressed years, and those who could pay would be charged double to make up for the destitute majority. This was the era of "Robin Hood medicine," with tired, overworked and underpaid physicians looking old by their fifties and dying at an early age. Patients were grateful, seeing doctors only when absolutely necessary, and often paying in kind (bushels of corn, dressed chickens, handyman services, even house cleaning). 
Hospitals were all non-profit, often religiously affiliated, and holding annual charity drives to make up huge shortfalls inasmuch as they treated everyone in spite of inability to pay, and especially children and the elderly. Then came prepaid healthcare, very little at first, but once it took hold the doctor-patient relationship has never been the same.

First on the scene were the so-called "Blues." To create the much needed revenue stream the hospitals organized into an organization named Blue Cross. For those who could afford a monthly premium, small by today's standards, any needed inpatient services were prepaid. In defense physicians organized into a parallel organization named Blue Shield that prepaid most outpatient services. In the 1930s the need for prepaid care was so intense that special laws were created for "medical services corporations" which enabled their success by exempting the Blues from the rigorous regulations and large reserves required of full-fledged insurance companies. This special legislation was later used to keep out other forms of prepaid healthcare. It should also be noted that mental healthcare was a stated exclusion.

During World War II when both goods and labor were in short supply, the government imposed ceiling prices on all commodities and wages. The newly created war industries needed to recruit from the farm belt tens of thousands of workers. Unable to use the inducement of higher wages, Henry J. Kaiser in his shipyards, as well as other industrialists in their aircraft and other war industries, hit upon the option of providing healthcare for workers and their families. Since healthcare was difficult to obtain in rural areas, the inducement worked, hundreds of thousands of farmers, moved to the industrial north and west, and employer paid healthcare was born and soon became a standard in the United States.

Amid accusations of "socialized medicine" by both the Blues and the American Medical Association, Kaiser after World War II brought his previously in-house health plan to the general public. Beginning in Northern California, it was prepaid healthcare purchased by employers or labor unions, and was based on capitation: the Permanente Medical Group received each month in advance a set fee for each enrolled member, and in return it provided all the care, both outpatient and inpatient, with no further fee or co-payment from the patient treated. Kaiser-Permanente as the first Health Maintenance Organization (or HMO, even before the name had been coined), so impressed the federal government in its delivery of quality care at efficient cost, in the mid-1970s Congress passed the HMO Enabling Act. Where heretofore HMOs were a California and Minnesota phenomenon, soon there were health maintenance organizations in all parts of the country, and were the precursors to managed care.
Little noticed by the health professions, in the mid1980s the U.S. Supreme Court ruled that healthcare was subject to antitrust and restraint of trade laws. This nullified the state laws forbidding the corporate practice of medicine. Almost simultaneously the Congress enacted DRGs, or "diagnosis related groups," which defined for over 400 diagnoses the maximum number of hospital days for which the federal government would pay. These two developments made possible and ushered in managed care and the rapid tethering of the spiraling healthcare rate of inflation. However, unable to write DRGs for psychiatry, it turned the problem of out-of-control costs for mental health over to the private sector, and managed behavioral health organizations (MBHOs) were created almost overnight. Foreseeing the birth of MBHOs, Cummings (1986; see also Cummings \& Fernandez, 1985) created a model whereby practitioners would still determine the course of behavioral care. Called American Biodyne, its tremendous success as a practitioner-driven $\mathrm{MBHO}$ was rejected as unnecessary by psychology and psychiatry. Furthermore, mental health professions ignored the need as well as their responsibility to contain runaway mental health costs (Fox, 2004), and soon our practice lost control of its own destiny. Perpetuating its anti-business bias and its economic illiteracy (Cummings \& O'Donohue, 2008), psychotherapists have seen a precipitous decline in their practices and in their incomes. Psychology is now the lowest paid doctoral health profession.

\section{Post World War II: The Birth of Non-Psychiatric Psychotherapy}

General William (Will) Menninger, chief psychiatrist for the U.S. Army during World War II, introduced many innovations, including the effective use of young, especially trained psychologists rendering immediate behavioral interventions in the battalion aid stations, tentstyle movable medical facilities just behind the battle front itself. To Menninger the need for immediate behavioral interventions was necessary to prevent onset of chronic mental states. Thus, he implemented the world's first integration of behavioral health into a primary care setting, a fact that has been lost in history. None-the-less, this and other mental health innovations were widely heralded in books and movies, and there arose a tremendous interest in psychotherapy. The demand far exceeded the supply of psychotherapists, and the Veterans Administration, as well as the National Institute of Mental Health, reasoning there would never be enough psychiatrists, created student stipends and educational funding not only for psychiatrists, but also for psychologists and social workers (Fig. 1). 


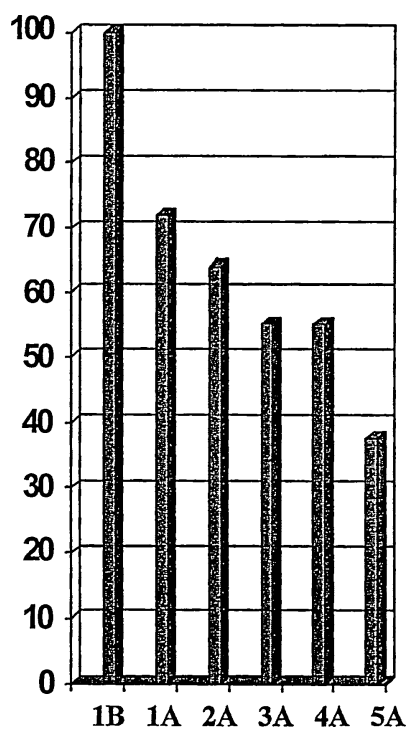

Fig. 1 Average medical utilization for the year before (1B) and the 5 years after (1A, 2A, 3A, 4A and 5A) behavioral intervention (Follette \& Cummings, 1967)

The combination of intense societal interest and public funding launched non-psychiatric psychotherapy, but it was not easy at first. Organized psychiatry opposed the private practice of psychology, fought its efforts toward licensure, and was joined paradoxically by the then academically controlled America Psychological Association. A 30 year battle ensued, and is chronicled in Wright and Cummings (2005), but as soon as doctoral clinical won the intense struggle, social work on a masters level followed in psychology's footsteps, soon to be joined by such newly spawned masters professions as marriage and family therapy (MFT) as well as counselors. Soon there was an oversupply of psychotherapists, over 700,000 as of this writing (Hogan, 2003), and although authorities recognize a great need in society for behavioral interventions, need does not necessarily translate into demand. The Golden Age of psychotherapy was over by the mid-1990s, done in by our insistence on long term (largely psychoanalytically oriented) psychotherapy, as well as the profession's refusal to address out-of-control mental health costs that exceeded for a time a $16 \%$ inflation rate. Controls were foisted upon the economically helpless psychotherapy practitioners, often arbitrarily, but ever so drastically.

\section{The Biomedical Revolution}

In the mid-1980s psychiatry began "medicalizing," a term denoting that it was becoming essentially a prescribing and hospitalization profession. Psychotherapy, was disdainfully referred to as "talk therapy," and was temporarily essentially lacking in psychiatric residencies. Recent requirements by the ACGME now require that psychiatric residents demonstrate competencies in several areas of therapy, including CBT, supportive, psychoanalytic, and group, but the medical aspects of psychiatry continue to be the primary focus. It also appears that the relatively few psychiatrists who still perform psychotherapy today tend to be over age 50 , and they practice largely in the Northeastern part of the country. DSM diagnostic categories have also been reformulated so that they resemble syndromes for which medication is the preferred treatment (Mojtabal \& Olfson, 2008).

Interestingly, however, up to $80 \%$ of psychotropic medications are prescribed by non-psychiatric physicians, a practice predicted two decades ago. The ever-prescient editor of the American Journal of Psychotherapy (Lesse, 1985) foresaw not only that medications would replace much of psychotherapy, but also that computers and a new, more easy to prescribe generation of psychotropic drugs with fewer side effects, would make it possible for primary care physicians to issue most of these medications. The past 10 years have seen referrals by physicians to psychotherapy fall by almost $50 \%$, while where once $95 \%$ of patients discharged from psychiatric hospitals were referred to outpatient psychotherapy, by 2005 the figure had fallen to only $10 \%$ (Cummings \& O'Donohue, 2008).

Despite a mounting number of studies that reveal serious psychotropic drug side-effects and even death, suicide or violence, especially among children, teenagers and the elderly (U.S. Department of Health and Human Services, 2008; Wiggins \& Cummings, 1998), it is anticipated that medication will continue to replace behavioral interventions until psychologists become an integral presence in the healthcare system.

\section{Where are our Patients?}

In its decades of insistence that psychotherapy is not an integral part of the medical system, two silos were created: a huge silo called physical health which gets the lion's share of funding (about 95\%), and a tiny, perpetually under-funded silo called mental health. In our paranoia that psychotherapy is not medicine, we failed to appreciate what dentistry, nursing, optometry, podiatry, and all other healthcare professions knew decades ago: it is healthcare that gets funded, not the esoteric mental health silo that suffers from stigma, quality concerns, lack of access, and insists on solo practices across town while healthcare has become essentially group practices congregating in convenient, easily accessible health centers near hospitals where all other healthcare professionals practice (Cummings, 2007).

Estimates are consistent for decades (see for example Follete \& Cummings, 1967 to Kroenke \& Mangelsdorf, 
1989) that $60-70 \%$ of visits to primary care are either reflecting psychological issues and emotional distress through physical symptoms that mimic physical disease, or they have psychological and lifestyle problems that are interfering with medical treatment or contribute to their non-compliance with medical regimens. Primary care physicians (PCPs) are constantly confronted with such patients, and they respond with medication and counseling to the extent that $85 \%$ of psychological problems are addressed by these PCPs. This makes the primary care system the de facto mental health treatment system in the United States. This is where our patients are!

\section{Integration, not Just Collaboration}

The entry of psychotherapy into the arena of healthcare occurred in the 1980s with the publication of the first extensive involvement of psychotherapy in direct collaboration with primary care physicians on a large scale. This is the so-called Hawaii Project I. A three-way contract among the Health Care Financing Administration, the State of Hawaii, and the non-profit Biodyne Institute launched an entirely new mental healthcare delivery system in which the Medicaid $(N=36,000)$ and federal employee $(N=$ $92,000)$ populations of Hawaii were randomized into the control group which received the extant health system, and the experimental group which was treated in the innovative delivery system. The Biodyne Model was 68 targeted, evidence based behavioral interventions, and working closely with physicians, the highest $15 \%$ of utilizers of healthcare were outreached. The purpose of the experiment was to test in a prospective, controlled setting the results of previous non-randomized research that revealed the medical cost offset effect: brief, targeted behavioral interventions resulted in reduction of medical/surgical costs far beyond the cost of providing the behavioral interventions (Cummings \& Follette, 1968; Follette \& Cummings, 1967). NIMH has already conducted 28 replications (Jones \& Vischi, 1979), but they, too, were retrospective studies (Figs. 2 and 3).

Recognizing this, there is an increasing effort in health psychology to increase collaboration between physical and mental health (Peek \& Heinrich, 1995), Beginning in 1997 there has emerged a system that goes beyond collaboration by integrating behavioral health into primary care by placing behavioral care providers (BCPs) into the primary care setting working side by side with PCPs. A growing number of textbooks have emerged, along with training programs that would train psychologists working in the primary care setting (chronologically some of these textbooks are Blount, 1997; Cummings, Cummings, \& Johnson, 1997; Cummings, O'Donohue, Hayes, \& Follette,

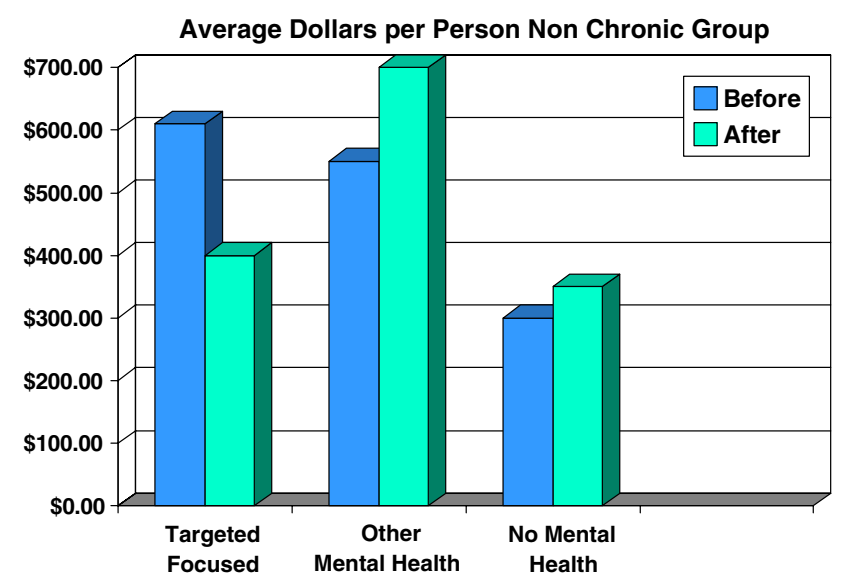

Fig. 2 Nonchronic group. Average medical utilization in constant dollars for the Hawaii project Nonchronic Group for the year before (lightly shaded columns) for those receiving targeted and focused treatment, other mental health treatment in the private practice community, and no mental health treatment (from Cummings, Dorken, Pallak, \& Henke, 1991)

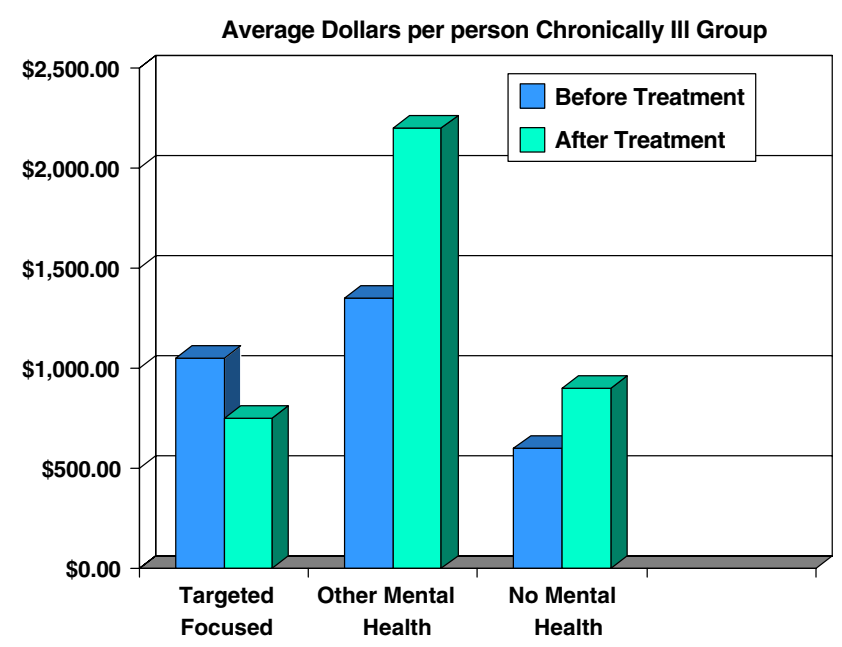

Fig. 3 Chronically ill group. Average medical utilization in constant dollars for the Hawaii project chronically ill group for the year before (lightly shaded columns) and the year after (darkly shaded columns) for those receiving targeted and focused treatment in the private practice community, and no mental health treatment (from Cummings et al., 1991)

2001; Cummings, O’Donohue, \& Ferguson, 2003, 2005; O'Donohue, Byrd, Cummings, \& Henderson, 2005; O'Donohue, Cummings, Cucciare, Runyan, \& Cummings, 2005; Robinson \& Reiter, 2007).

One of the earliest demonstrations in which especially trained behavioral care providers (BCPs) were co-located with PCPs in the primary care setting was the Hawaii Integrated Healthcare Project II (Laygo et al., 2003), funded by the federal government. About the same time, the U.S. Air Force integrated its medical system worldwide (Runyan, Fonseca, \& Hunter, 2003). There have been a number of successful examples of the integration of 
behavioral health into primary care in TriCare, the Cherokee Health System, Veterans Administration, and the U.S. Navy, but until Kaiser Permanente in Northern California retooled their delivery system accordingly, the private sector had lagged behind. As the data emerge, there are a number of characteristics attributable to appropriately conducted integrated behavioral/primary care. Unfortunately, there are examples of so-called integrated primary care that fall far short of adequate delivery of care, either because of insufficient training of the BCPs, or the lack of orientation of PCPs in the effective use of the system. Furthermore, there exists a widespread lack of appreciation by administrators of the complexity of the system. The attitude, "Oh, this is simple to do," results in a system that simply is not!

- Integrated care results in $85-90 \%$ of patients in the hallway hand-off entering treatment, while in the traditional referral system only $10 \%$ do so.

- There is a $20-30 \%$ reduction in medical costs above the cost of the behavioral care (see Cummings et al., 2003, for a review).

- There is a leveraging of physicians, inasmuch as they are freed to perform more remunerative medical procedures for which they are better trained.

- The ideal ratio of BCPs to PCPs is $1: 6$, but it is important that there be at least two BCPs so that while one is doing the treatment, the other is available for the hallway hand-off (Fig. 4).

- Following behavioral intervention, there is an increase in compliance with medical regimen, and often a significant change in life style.

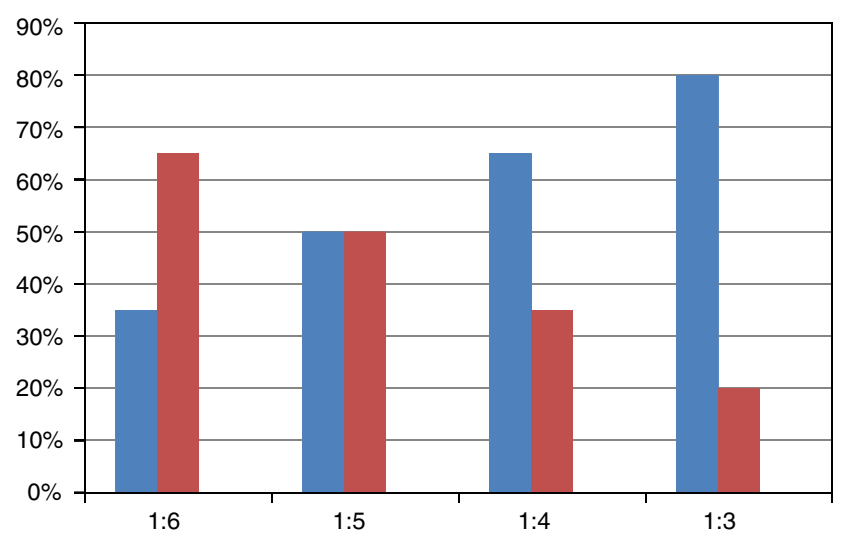

Fig. 4 Composite schematization of the increases in the percentage of psychiatric/psychological treatment that can be conducted in primary care as a function of the ratio BCP to PCPs, whether it is 1:6, $1: 5,1: 4$ or $1: 3$. Compiled 2008 by the Cummings Foundation Behavioral Health from data reported by family medical practices in Arizona and California. The second bar in each subset indicates the declining percentage of such patients that remain to be referred to speciality psychiatric care (e.g., only $20 \%$ with the $1: 3$ ratio)
- Physicians are relieved of having to deal with patients who have broken down emotionally in their offices, a frequent occurrence that takes much time, creating havoc with the usually tight schedule.

- Physicians are spared the apprehension that at any time they may be confronted with emotionally distraught patients in their offices or on the telephone at night or weekends.

- Depending on how aggressively one constructs the system, from 40 to $80 \%$ of specialty mental health care can be conducted in the primary care setting, so that specialty care is limited to chronic cases.

\section{Quality Assurance}

In the delivery of mental and behavioral care services too often the need for quality assurance is neglected, resulting in needless substandard care and even questionable interventions. At American Biodyne, even after the rigorous retraining affectionately dubbed the "Biodyne Bootcamp," fully $15 \%$ of clinicians' time was spent in quality assurance. This included a 3 hour case conference each Friday morning in which the staff eagerly presented their failures or near-failures, one-on-one supervision, and group supervision. Such an expenditure of time was and continues to be startling to both the practitioners and the industry, but recent extensive research by Scott Miller (2008) and his colleagues demonstrates that the one feature that determines the master psychotherapist (defined as effectiveness) is constant evaluation and feedback. This investment at Biodyne was reflected in the total absence of malpractice claims: in 10 years with 25 million enrollees and 10,000 psychotherapist, there was not a single malpractice claim or a patient complaint that had to be adjudicated. When Biodyne passed into new hands in 1992, one of the first features eliminated was the $15 \%$ of time devoted to quality assurance. Within months malpractice suits began to appear.

Quality can be defined as "exceeding your customer's expectations." Quality improvement should be continuous - the bar is always moving higher. Quality always requires consistent measurement to determine the extent to which these objectives are being achieved. Because behavioral health has not embraced the quality ethic, there is precious little data to determine the extent to which we even come close to our customer's expectations. However, there are plenty of reasons to be concerned.

We also have to be careful to define who our customers are. Clearly one focus has to be on the patient. If they do not like what we are providing, then they simply will not show up in the first place (e.g., they go to their primary care 
physician for their problem); or they can simply stop attending (the modal number of psychotherapy sessions is one). Many health professionals now have wonderful waiting rooms (e.g., pediatric dentists have high quality arcade games and flat screen TVs), incentive systems for compliance (the orthodontist of the second author's children rents the swimming park the last day of the season exclusively for compliant patients), have developed additional services and procedures that customers want (teeth whitening, sealants), have invested in electronic medical records that vastly decrease errors (there is a saying now in medicine that "paper kills"), and have promoted evidencebased practice to decrease unwanted variability in practice patterns. All these have created more satisfied patients.

However, another customer is the third party payor. In behavioral health there is actually a stream of payors, usually consisting of such care management organizations such as Magellan, Value Options, Cigna, etc., who often have contracts with an HMO (such as United or Blue Cross/Blue Shield) who in turn contracts with an employer, union, or a federal government agency (e.g., Department of Defense). Each of these payors care about the value they receive for their dollar; i.e., they have expectations that we, in taking a quality perspective, try to exceed. As a profession we have not understood what the expectations of these organizations are, we have not innovated in trying to meet these, and we have not measured on dimensions that might impress them. Instead, we have vilified our payors, spent a lot of money suing the folks who write our paychecks (i.e. APA has spent over 10 million dollars in such lawsuits). When we do measure, our efforts often fall short of what might interest the payor, especially if it is an employer. Typically, for example, our outcomes research, if any, might focus on BDI scores, but not measure anything related to missed workdays or medical utilization, both vital to our customer.

The quality problem in behavioral care services is often the elephant in the room when business decisions are being made. Part of the reason why people may go to their PCP is that this individual is more trusted than the mental health practitioner. Surveys of patients have revealed that they are concerned both about the effectiveness of mental health interventions as well as the "normality" of mental health practitioners. We are too often seen as strange and ineffective, a perception that may not be all that delusional. It is important that integrated care does not adopt this same quality problem, for integrated care is doomed if it merely co-locates something resembling a Rorschach administering, rebirthing psychotherapist who is simultaneously dealing with his or her own issues.

Such a flaky, non-evidence based, ineffective and even deleterious practitioner invokes in the patient what economists call the "lemon problem." Value of a product (and astonishingly psychotherapists still do not see their services as a product) determines the price the customer is willing to pay, while the consistency of the quality is directly related to price. A customer will pay the price, for example, for milk that has value: consistent high quality, absence of contamination, curdling, or skimming. If two-thirds of the time the milk manifests lowered quality in the form of one or more of these quality-problems, the price will drop dramatically, or the customer may switch to soy milk. When the latter occurs the price may drop below the cost of producing it, and milk might disappear from the store shelves altogether. Consider, then, if the public perception is that psychotherapy is effective only occasionally, or not at all, or that the practitioner suffers from psychological issues of greater magnitude than the patient, the demand for such services diminishes while at the same time our educational system has produced a glut of psychotherapists (Cummings \& O’Donohue, 2008).

We, as a profession, have conveniently blamed price depression on the greed of managed care. Some of this is true, as there are good as well as bad quality managed care companies, but it is not clear what we can do about this. We can, however, address the factors under our control. We as a profession have ignored quality factors, and several national mental health organizations have neglected to adopt and enforce quality improvement practices that are substantive. Only then can we reverse the price depression in psychotherapy (see O'Donohue \& Fisher, 2007, for more on quality improvement in mental health).

\section{Funding of Integrated Care}

Integrated behavioral/primary care is like a pomegranate: overwhelmingly people say they like it, but few buy it. It has often been pointed out that in healthcare it is 20 years after the proven effectiveness of a treatment before it is fully adopted. In this point of view, it will be 10 more years before integrated care is mainstream. Aside from this, however, what are some of the impediments?

\section{Public Funding}

The military, TriCare and the Veterans Administration have been at the forefront in funding demonstration projects. This has been made possible through top-down decisions, and it has been facilitated by the fact that all of these demonstrations are in staff model delivery systems rather than networks. Invariably these demonstration projects have been showered with high praise and general satisfaction, but when the funding dries up the heretofore successful delivery system is allowed to wither and dry up. Even in the one extensive private system in which 
integrated care has been acknowledged and mandated, some of the Kaiser Permanente Medical Centers have been allowed to opt out or lag behind.

\section{Private Funding}

In the 1990s the managed care organizations, including the managed behavioral health organizations (MBHOs, commonly referred to as "carve-outs"), began to morph out of managed care. MBHOs took an active part in the delivery of services and even made service decisions. This later shifted towards care management, in which they manage the benefit but do not tell the doctors how to practice in their offices. Much of this was in response to an outcry from both the practitioners and the public.

The current care management organizations like and support the concept of integrated behavioral/primary care, would welcome the effectiveness of such an innovation, and would be willing to create payment mechanisms through which BCPs could be reimbursed. However, they can not direct professionals to practice in this manner. The question then arises: how is this to be funded? It is time for practitioners to rise to the occasion, paying attention to the following considerations.

Every industry attempts to become more efficient. Competition is a key driver in this pursuit, for if a competitor can provide the same or higher quality service (or product) at a lower price than you can, you will soon be driven out of business. Economists call this process in the competitive marketplace "creative destruction," and it behooves our profession to become more productive and efficient. How is this to be done, for in the current marketplace the majority of the American public is not convinced that psychotherapy is of greater value (cost, time expended, outcomes) than psychotropic medication.

Integrated care as a model of service delivery achieves increased efficiencies because it places services where folks seem to want it—one stop shopping in their primary care physician's office. It also allows the practitioner to be more productive by adopting a number of practice standards that differ from standard mental health specialty care (whether in private offices or mental health clinics and centers):

- Brief, evidenced-based assessment (not utilizing MMPIs, Rorschach Tests, or extensive history).

- Consultation liaison models (the BCP is seen as an extender of the physician and augments the PCP's treatments without taking over the patient and starting anew).

- Focused, evidence-based interventions save time and money.
- Providing interventions to evidence-based groups is possible because of the large number of patients with a particular behavioral problem (e.g., obesity, chronic pain, depression, non-compliance with medical regimen).

- The standard is restoring functioning rather than complete cure or personality restructuring.

- There is a wider scope of practice. The BCP is not just a specialist in DSM problems but also effectively treats sub-clinical problems, pathways to medical utilization (e.g., stress, noncompliance) as well as behavioral medicine interventions (e.g., chronic pain, obesity).

The premise for arguing for integrated care is that clinicians practicing in this way can decrease over-all medical costs. The argument is not that we will help you find more money, but that the money is already there if you rearrange the way funds are being spent now and you will have healthier patients, demanding fewer medical services, as well as extra funds left over.

\section{The "Laboratory Model" of Integrated Care}

Most practicing psychotherapists see patients all of whom belong to a variety of third party payers. Consequently, BCPs are economically unable to contract directly in a special network with one carrier as the patient flow would probably not be sufficient. Medical laboratories faced this same problem, and solved it decades ago. Physicians are "herd animals:" they congregate in medical centers and serve many surrounding physicians' offices, as well as many health plans. The key is proximity and immediate accessibility, a successful model that a number of psychologist groups practicing integrated care have replicated.

A number of psychologists in scattered locations around the country have also persuaded family medical group practices to include one or more BCPs. When the group practice is large it is easy to have more than one $\mathrm{BCP}$, but economics limits a group of five or six physicians to just one BCP. This precludes the ability to have one BCP always available for the hallway handoff while the other is doing the treatment. Through accommodated scheduling, however, these limitations can be largely overcome.

\section{Difficulties, Perverse Incentives and Inadequate Implementation}

The road to integrated behavioral/primary care has not been, and will not be easy. There are a number of key difficulties and even perverse incentives (economists call 
them "moral hazards") in the field. Here is a brief listing of the major financial difficulties.

- Chief financial officers (CFOs) require a fairly sophisticated return on investment analysis (ROI) that will compare a proposal to all other possible investments. Integrated care is competing for scarce dollars against such alternative investments as disease management programs, hiring more employees that can bill additional amounts, or even against new information systems such as electronic medical records, all of which presuppose savings. Promoting integrated care needs to generate clear and credible financial data that can be compared to these alternative investments. Currently there is a paucity of such data. These data need to show that in population x (e.g., urban Medicaid) an investment of $y$ will produce a ROI of $z$ (usually a return of 5 to 1 , a difficult goal to achieve in the 12-month period favored by CFOs).

- The outcome data that exist for integrated care are often missing key financial outcomes (e.g. impact on medical utilization, disability payments, or absenteeism).

- Perverse incentive abound. Healthcare budgets are usually constructed from that of last year. If integrated care decreases costs, a smaller next year's budget may result. In federal funding, the government often demands that any saving be sent back to Washington, removing local incentives to save money.

- A lot of innovation is going on in healthcare, often producing "innovation fatigue:" management does not want to administer one more innovation.

- One of integrated care's competitors is nurse-driven disease management that has proliferated into a several billion dollar industry. These programs appear to be less risky to managers, they often have impressive ROI data, and they do have some positive clinical impact. However, they are not a panacea. They can be useful in the easiest cases but are no substitute for astute clinicians dealing with the complex cases found in integrated care (see Cummings, O’Donohue, \& Naylor, 2005). However, comparative studies are needed to show the relative advantages and disadvantages of these programs. Ideally, they should complement each other.

- Many insurers will not pay for behavioral health consultation codes. In fee-for-service environments these are essential in supporting integrated care as it allows the BCP reimbursement for non-DSM problems (e.g., chronic pain, treatment compliance).

- Medicaid does not allow for medical and behavioral billing on the same day, an archaic regulation unsuccessfully intended to prevent fraud, that essentially stops the hallway handoff in its tracks.
- Although there are now a number of large-scale integration systems (e.g., the Air Force, Veterans Administration, Army and Navy, TriCare, Cherokee Healthcare, Kaiser Permanente), there is perhaps even a larger number that are poorly constructed and are jeopardizing the concept by predictably poor and even negative results. These range from collaborative models that maintain the two silos, or ones that employ BCPs who are not trained to adequately provide empirically based services in integrated care settings.

\section{Summary and Conclusions}

The recent precipitous decline in referrals for psychotherapy has rekindled the need for reevaluation of psychology's long-standing and self-defeating stance that we are not part of the healthcare system. America pays for healthcare, not psychosocial care, and all other professions rendering treatment (e.g., dentistry, nursing, osteopathy, optometry, podiatry) have taken advantage of the nation's evolution from a medical system to a healthcare system. As part of this healthcare system they are prospering, while psychotherapy is languishing.

The integration of behavioral health into primary care, in which behavioral care providers (BCPs) are co-located in the primary care setting alongside primary care providers (PCPs) has evolved in the last decade as a successful, viable method of bridging this gap. Many impediments to successful implementation persist, and these range from the reluctance of mental health practitioners to give up solo practice, the 50-minute hour, and their traditional mode of practice; archaic training models that don't prepare psychologists to provide integrated care; to the fact that our current third-party payor system is not constructed to meet the funding of this evolving system. Henry J. Kaiser, the industrialist hero of World War II who built the Victory ships often in five days from keel to launch and saved Great Britain, and who through Dr. Sidney Garfield founded the Kaiser Permanente system, would admonish, "Find a need and fill it." The need has been found, but filling it will require boldness and innovation from psychological practitioners.

Fortunately, there are now a few, state-of-the-art training programs specifically designed to produce practitioners who are prepared to provide integrated care about to debut by 2009. It is the strong belief of the authors that those will more appropriately emerge from the health sciences divisions of medical schools rather than through traditional clinical psychology doctoral programs. 


\section{References}

Blount, A. (Ed.). (1997). Integrated primary care: The future of medical and mental health collaboration. New York: Norton.

Cummings, N. A. (1986). The dismantling of our health system: Strategies for the survival of psychological practice. American Psychologist, 41, 426-431.

Cummings, N. A. (2007). Treatment and assessment take place in an economic setting, always. In S. O. Lilienfeld \& W. T. O'Donohue (Eds.), The great ideas of clinical science (pp. 163-184). New York: Routledge (Taylor and Francis Group).

Cummings, N. A., Cummings, J. L., \& Johnson, J. N. (Eds.). (1997). Behavioral health in primary care: A guide for clinical integration. Madison, CT: Psychosocial Press.

Cummings, N. A., Dorken, H., Pallak, M. S., \& Henke, C. J. (1991). The impact of psychological intervention on health care costs and utilization: The Hawaii Medicaid Project. HCFA Contract Report \#11-C-983344/9.

Cummings, N. A., \& Fernandez, L. (1985). Exciting new opportunities for psychologists in the market place. Independent Practitioner, 5, 38-42.

Cummings, N. A., \& Follette, W. T. (1968). Psychiatric services and medical utilization in a prepaid health plan setting: Part 2 . Medical Care, 6, 31-41.

Cummings, N. A., \& O'Donohue, W. T. (2008). Eleven blunders that cripple psychotherapy in America: A remedial unblundering. New York: Routledge (Taylor and Francis Group).

Cummings, N. A., O'Donohue, W. T., \& Ferguson, K. E. (Eds.). (2003). Behavioral health in primary care: Beyond efficacy to effectiveness. Cummings Foundation for Behavioral Health: Health utilization and cost series (Vol. 6). Reno, NV: Context Press.

Cummings, N. A., O’Donohue, W. T., \& Ferguson, K. E. (Eds.). (2005). Psychological approaches to disease management. Cummings Foundation for Behavioral Health: Healthcare utilization and cost series (Vol. 8). Reno, NV: Context Press.

Cummings, N. A., O'Donohue, W. T., Hayes, S. C., \& Follette, V. (Eds.). (2001). Integrated behavioral healthcare: Positioning mental health practice with medical/surgical practice. San Diego: Academic Press.

Cummings, N. A., O’Donohue, W. T., \& Naylor, E. V. (2005). Psychological approaches to disease management. Reno, NV: Context Press.

Follette, W. T., \& Cummings, N. A. (1967). Psychiatric services and medical utilization in a prepaid health plan setting. Medical Care, 5, 25-35.

Fox, R. E. (2004). It's about money: Protecting and enhancing our incomes. Independent Practitioner, 24, 158-159.

Hildebrand, J. (2008). As quoted in the business of life. Forbes, September 1, p. 120.

Hogan, M. F. (2003). New Freedom Commission Report: The President's New Freedom Commission-recommendations to transform mental health care in America. Psychiatric Services, $54,1467-1474$.
Jones, K. R., \& Vischi, T. R. (1979). The impact of alcohol, drug abuse, and mental health treatment on medical care utilization: A review of the research literature. Medical Care, 17(suppl.), 43131.

Kroenke, K., \& Mangelsdorf, D. (1989). Common symptoms in ambulatory care: Incidence, evaluation, therapy and outcome. The American Journal of Medicine, 86, 262-286.

Laygo, R., O'Donohue, W., Hall, S., Kaplan, A., Wood, R., Cummings, J., et al. (2003). Preliminary results from the Hawaii Integrated Healthcare Project II. In N. A. Cummings, W. T. O'Donohue, \& K. E. Ferguson (Eds.) Behavioral health as primary care: Beyond efficacy to effectiveness. Cummings Foundation for Behavioral Health: Healthcare utilization and cost series (Vol. 6, pp. 111-143). Context Press Reno, NV.

Lesse, S. (1985). The future of the health sciences: Anticipating tomorrow. Northvale, NJ: Jason Aronson.

Miller, S. D. (2008). www.BaloneyWatch.com.

Mojtabal, R., \& Olfson, M. (2008). National trends in psychotherapy by office-based psychiatrists. Archives of General Psychiatry, $85,41-49$

O’Donohue, W. T., Byrd, M. R., Cummings, N. A., \& Henderson, D. A. (Eds.). (2005). Behavioral integrative care: Treatments that work in the primary care setting. New York: Brunner-Routledge.

O’Donohue, W. T., Cummings, N. A., Cucciare, M. A., Runyan, C. N., \& Cummings, J. L. (Eds.). (2005). Integrated behavioral health care: A guide to effective intervention. Amherst, NY: Humanity Books (Prometheus).

O'Donohue, W. S. T., \& Fisher, J. E. (Eds.). (2007). Practitioners guide to evidence-based psychotherapy. New York: Springer.

Peek, C. J., \& Heinrich, R. L. (1995). Building collaborative healthcare organizations: From idea to innovation. Family Systems Medicine, 13, 327-342.

Robinson, P. J., \& Reiter, J. T. (2007). Behavioral consultants and primary care: A guide to integrating services. New York: Springer.

Runyan, C. N., Fonseca, V. P., \& Hunter, C. (2003). Integrating consultative behavioral healthcare into the Air Force medical system. In N. A. Cummings, W. T. O’Donohue, \& K. E. Ferguson (Eds.), Behavioral health in primary care: Beyond efficacy to effectiveness. Cummings Foundation for Behavioral Health: Healthcare utilization and cost series (Vol. 6, pp. 145-163). Reno, NV: Context Press.

U.S. Department of Health and Human Services. (2008). Antipsychotic medications linked to deaths in elderly patients. DHHS News release, August 23, Author.

Wiggins, J. G., \& Cummings, N. A. (1998). A national study of the experience of psychologists with psychotropic medication and psychotherapy. Professional Psychology, Research and Practice, 29, 549-552.

Wright, R. H., \& Cummings, N. A. (Eds.). (2005). Destructive trends in mental health: The well-intentioned path to harm. New York: Routledge (Taylor and Francis Group) 